\title{
The Application of Mind Map in English Reading Class
}

\author{
Yi Lu, a and Mu Sun ${ }^{2, b}$ \\ ${ }^{1}$ Jilin Business and Technology College, No.1666 Calun Lake Street, Changchun, Jilin Province, \\ China \\ ${ }^{2}$ Changchun University of Science and Technology, No.7089 Weixing Road, Changchun, Jilin \\ Province, China \\ aluyi0820@163.com, b172792256@qq.com
}

Keywords: Mind map; English reading; Reading procedure; Application

\begin{abstract}
The application of mind map in the teaching of English reading can make the difficult and complex contents clear and easy, and it will help students understand the text and knowledge deeply and organize and memorize reading materials easily. It is also helpful to do writing exercises by organizing language materials. This paper takes some reading passages as examples, introduces how to use mind maps in the three reading procedures: pre-reading, while-reading and after-reading to organize the teaching plan. The application of mind map in the reading class will promote students to use the schema of language, contents and forms to understand the text effectively and to improve their reading abilities, and develop the ability of speaking and writing by reading exercises.
\end{abstract}

\section{Introduction}

Mind map is also called brain map, mental map, and it is first created by famous British educator Tony Busan in 1960s. He is also named "Mr. Brain". Mind map is a way to externalize the radioactive thinking, and it helps us understand and memorize information by dividing knowledge frame. [1] It usually needs color, lines, signs, vocabulary and image to help brain memorize things. The using of mind map can not only improve our memory, but also increase our creativity and imagination.

\section{The Guidance of Schema Theory and the Application of Mind Map}

In the teaching of English reading, the author takes the schema theory as the guidance, and designs three reading process: pre-reading, while-reading, and after-reading by using mind map. The following is the introduction of the application of map mind in the three designed procedures of reading teaching.

Pre-reading. The aim of pre-reading task is to make students search for and know the relevant information about the reading materials, and activate the background information in mind, and predict the contents which mainly involved in the passage. The more familiar students get with the text, the less difficulties they will meet in reading. Now let's take the pre-reading design of a text from Unit 2 "Do You Want to Watch a Game Show" as an example, and present the application of mind map.

The teacher makes conversations with students, and draws pictures during the process of the conversation. The following is Picture 1, and here is the conversation: 


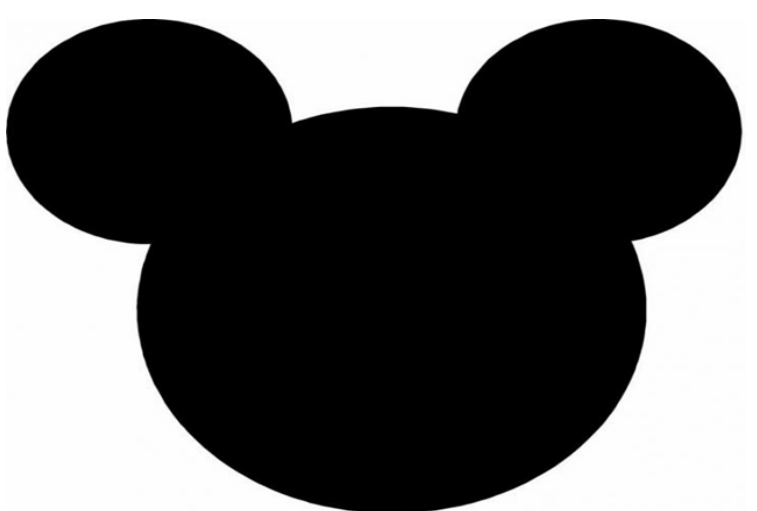

Picture 1: The head of Mickey Mouse

T: I've drawn a cartoon character on the blackboard. Do you know who it is?

Ss: Yes, it is Mickey.

T: What do you know about Mickey?

S1: It is a black mouse with two large round ears.

T: Yes, it is easy to draw it on the blackboard. It is quite simple. What else do you know about him?

S2: I know that his girlfriend is Minnie, another cartoon character.

S3: I think he is very popular and I love him very much.

T: Me, too. Many people like him. He is popular and famous. Do you know who created Mickey?

Ss: Disney.

T: Yes, Walt Disney. He was a great man. Because of Mickey Mouse, a simple and little mouse, Walt Disney became rich and successful. Now we are going to read an article about Mickey. What will the writer talk about in the article? Can you guess?

S4: I think the writer will talk about why Mickey is so popular.

S5: I think the writer will tell us something about Walt Disney.

$\mathrm{T}$ : Maybe. Let's read the article and see if your predictions are right.

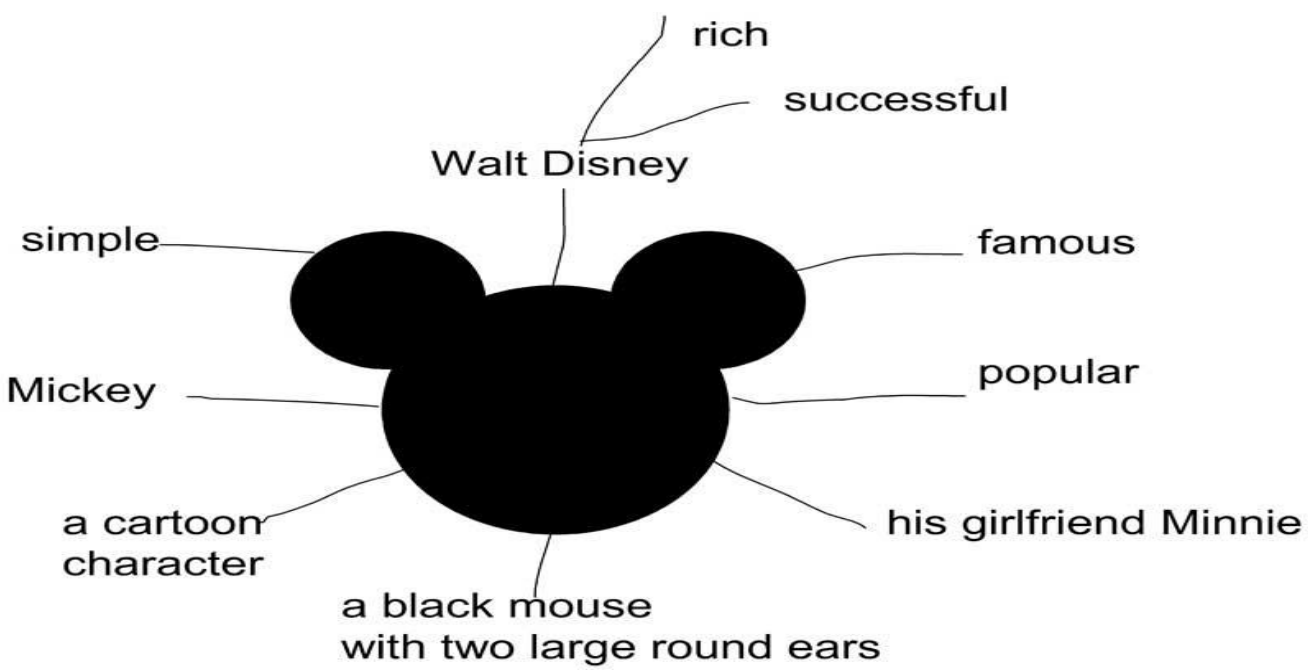

Map 1: The mind map of picture 1 with some key words

The image can attract students' eyes and attention automatically, and it can trigger tons of imagination.1 It is helpful to the reciting. By drawing the Brief strokes of Mickey Mouse, the teacher leads in the subject of the text picturesquely and vividly. The more vividly one imagines, the more effectively he recites. [2] Picture 1 triggers students' imagination and memory. Then the teacher asks:" What do you know about Mickey?" Students say much information about Mickey Mouse, and in the process of asking and answering, the new words which are barriers in the understanding will appear, such as, cartoon character, simple, girlfriend, rich, successful, the 
teacher will add them in the mind map, and also adds the key words, including Mickey, Minnie, Walt Disney, popular, famous and a black mouse with two large round ears to the mind map. In this way, the teacher presents the new language points, and motivates students' old knowledge, and provides them with relevant language schema. Pre-reading process not only makes students be familiar with subjects of the text, activate their language schema, but also gives students new language schema, and makes them understand the text contents more effectively.

\section{While-Reading}

The aim of while-reading is to get main information form the text. The teacher should use the information transformation method, and design the effective tasks and activities from the perspective of overall understanding, and present the contents of the text vividly and clearly by using the complete visual image. [3] The following is an example taken from the text of Unit 4"I'm Going to Study Computer Science."

\section{Task 1 skimming}

Let students skim the passage and find the topic sentence for each paragraph, and some key words. The aim of this task is to train students' skimming skills. Teachers should tell students skimming is just reading some parts of the text, and getting the whole understanding of the passage. [4] Students find the topic sentences for the three paragraphs: "Do you know what a resolution is? /There are different kinds of resolutions. /Although there are differences, most resolutions have one thing in common." And find the key words: resolution, different kinds of resolutions and the resolutions have one thing in common.

\section{Task 2 skipping}

Let students skip the first and second paragraphs, and find out some details which support the topic sentences. First, let students read the diagram, make sure they know the information in the picture. See the first paragraph, let take the topic of resolution as an example, discuss the meaning of resolution, the common resolutions, when to make a resolution, why to make a resolution and how to make a resolution. See the map as followed:

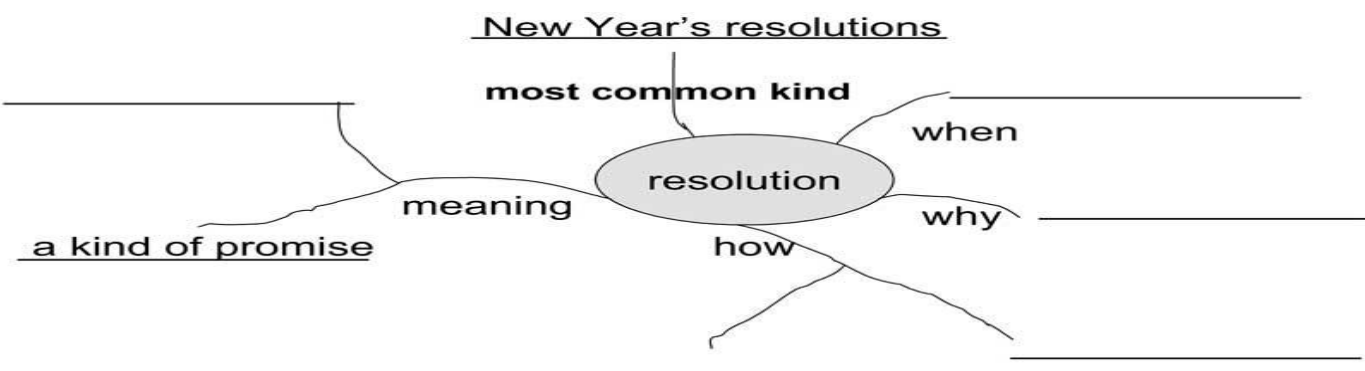

\section{Map 2: A mind map about resolution}

Map 2 shows we take different resolutions as the topic, and introduce the 3 different branches: physical health, better planning and self-improvement, and let every branch has further branches to explain the concrete expression form for each kind of resolution. After filling in the diagram, tell students the sentences after the topic sentence are usually supportive detailed information, and let students fill the relevant information in map 2 and 3. Before filling in the blank, the teacher should tell students that skipping is an eye -browsing for the specific information, and it is a process for searching certain information. [5] 


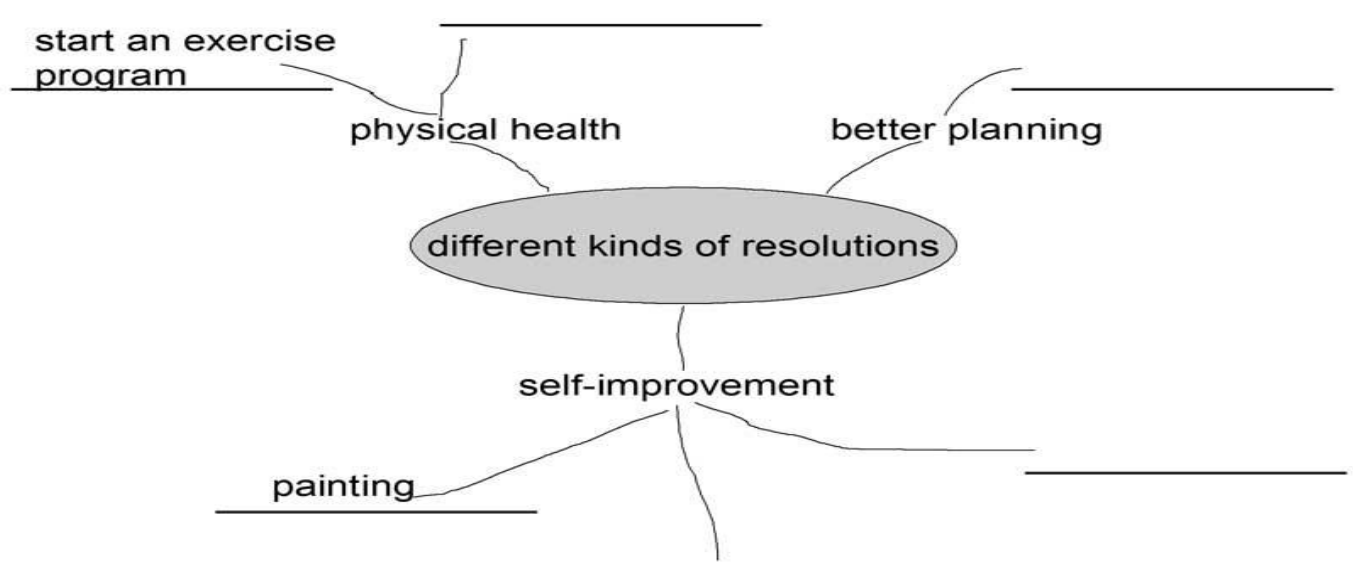

Map 3: The mind map about different kinds of resolutions

Task 3 Intensive reading

Let students read the passage carefully, and fill in the mind map. First, lead students read map 4:

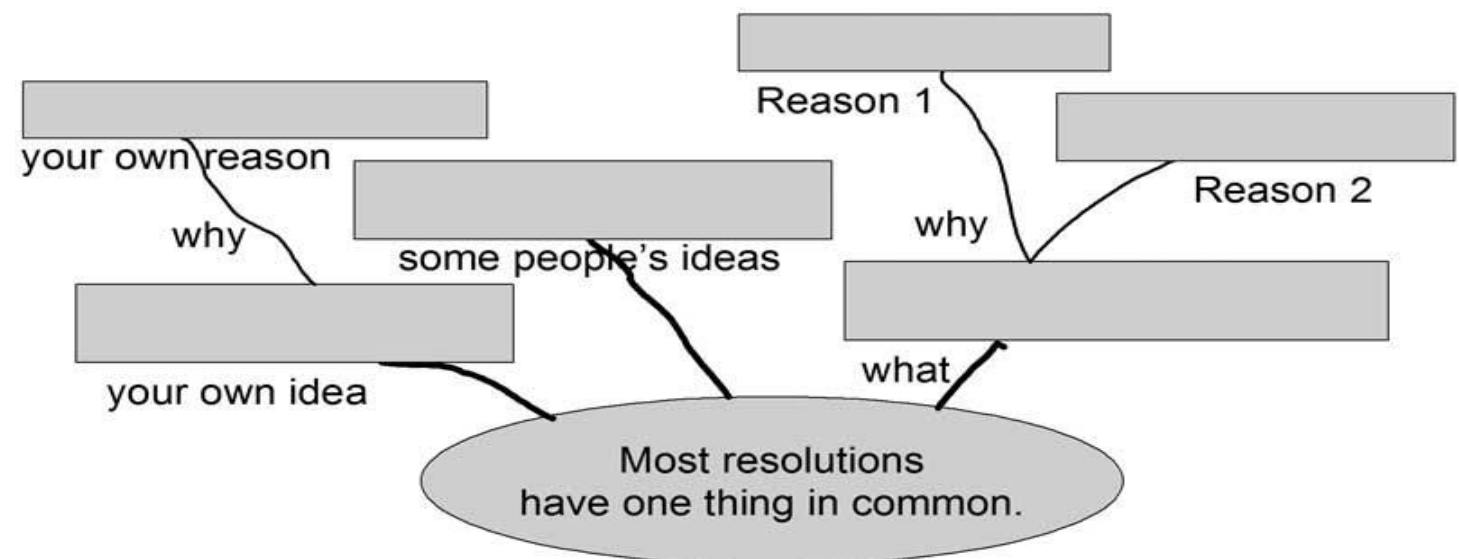

Map 4: The mind map about the common character most resolutions have

Map 4 takes the identity of resolution as the topic, and develops the topic from three angles: What things they have in common? And why? / People's views on resolutions? / Your views and reasons. The answers of the first and second questions can be found in the text, and the third one need students understand and understand the text carefully and then state their own points.

Before reading, the teacher should show how to read the text intensively to students. Under the guidance of the teacher, students get the effective information by intensive reading, and express their own views by inference and judgment, and fill the blanks in map 4. Create an appearance in the mind map will help you organize more data in the recalling forms. [6] Map 4 connects the topic sentences and key words with a tree diagram.

The difficulty of the above three tasks is increasing gradually, step by step. These activities also motivate students' language, contents and schema, and improve students' reading comprehension and memory effects, and cultivate their mental ability.

After-reading. To strengthen students' understanding for the text, the after-reading tasks are necessary. These tasks can be designed as oral and written forms.

Retelling. The teacher can give students a topic, for example, "Jim's life in ten years", let students say some words from the aspects of clothes, sports, places, job, pets, etc., at the same time, teacher draws the mind map according to the words students give. Then give students several minutes to speak a long passage about the topic, and they can use the words on mind map, but they should organize their own language and add something new.

Writing an article by using mind map. Give students a topic, for example, "My life in ten years", let students draw their own mind map, firstly think about the branches, and then details to support each branch. Then the composition is just organizes the contents in mind map in a good way. 


\section{References}

[1] Chai Shaoming, Ding Meirong, The Application of Computer-supported Mind Map in the College English Teaching, J. Chinese Educational and Technological Equipment, 8(2006).

[2] Chenmin, Mind Map and its Application in English Teaching, J. Foreign Language Educational Technology, 1(2005):89-92.

[3] Guo Xiaobing, A Discussion of English Reading in Higher Vocational School, J. Shanxi Youth, 21(2016): 25-29.

[4] Ji Manran, The Inspiration of Mind Map on the English Vocabulary Teaching, J. Modern Education Forum, 1(2010): 58-59.

[5] Liu Xiaoning, The Summary of Mind Map Research in China, J. Journal of Sichuan Education College, 5(2009):52-55.

[6] Paul Farrand, Enid Hennessy, The Efficacy of the Mind Map Study Technique, J. Medical Education, 5(2002), 101-105.

[7] Pei Guanggang, Mind Map and Foreign Language Teaching, J. Shandong Foreign Language Teaching, 2(2007): 59-62.

[8] Rumelhart DE, Ortony A, The Representation of Knowledge in Memory, J. Schooling and the Acquisition of Knowledge, 2(1977) 12-15.

[9] You Xiaonan, The Application of Mind Map in the English Teaching, J. Professional Circle, 9(2007): 45-46.

[10]Zhao Guoqing, Lu Zhijian, Concept Map and Mind Map, J. China Educational Technology, 1(2005), 56-60. 